\title{
Application Research of Topographic Slope as A Proxy for Seismic Site-Conditions and Amplification in China Earthquake Risk Assessment
}

\author{
Jian Zhou ${ }^{1,2}$, Xiaojun $\mathrm{Li}^{1}$, Kun Chen ${ }^{1}$, Xiaoqing Wang ${ }^{3}$, Jian $\mathrm{Wu}^{1}$ \\ ${ }^{1}$ Institute of Geophysics, China Earthquake Administration, Beijing 100081, China \\ ${ }^{2}$ China Earthquake Administration, Beijing 100036, China \\ ${ }^{3}$ Institute of Earthquake Science China Earthquake Administration, Beijing 100036, China
}

\begin{abstract}
The method of using topographic slope as a proxy for seismic site-condition and amplification, which was introduced in USGS open-file report 2007-1357, was applied to generate the Building Earthquake Risk Map for Mainland China in national scale and Earthquake Risk Assessment for Songming City in regional scale. The study illustrated the feasibly of using topographic slope as a rapid approach for site-conditions and amplification in earthquake risk assessment in national and regional scale.
\end{abstract}

Keywords: Topographic, USGS, Sitecondition, Hazard, Risk Assessment, China

\section{Introduction}

Earthquake risk assessment begins with hazard identification, which focus on the distribution of strong ground motion, faults and violation of Geo-earthquake disasters, like liquefaction affection, basement malfunction, etc.

To estimating the strong ground motion, which represents the hazard level. Character of surficial materials and site-condition should be considered due to its dramatic effect on amplification of strong ground motion on rock site. How to estimating the site-condition comes into a critical process in earthquake risk assessment. Field investigation and geophysical prospecting can be applied in determining the site-condition in a special site. Alternatively, in rational and regional scale, due to unavailable of database of soil dynamics parameters in target area and timelimit of special project, a rapid method to estimate the site-condition is necessary to develop.

The method of topographic slope as a proxy to estimate site-conditions is introduced, then amplification factors of ground motion on rock site in study area are introduced to get ground motion map on regolith to represent the hazard. The hazard map is combined with building census information and structure vulnerability models to produce risk map in national and regional scale.

\section{Application in National Scale}

\subsection{Information of Ground Motion on Rock Site}

Data of ground motion distribution on rock site applied in this study is derived from the result of Seismic Ground Motion Parameter Zonation Map of China (GB18306- 
2015), which uses $50 \mathrm{a} 10 \%$ and $100 \mathrm{a} 1 \%$ ground peaking acceleration(GPA) as parameters. The value of GPA is vector information, but considering the accuracy level of topographic slope which will be used in next stage of the study. The vector GPA information is linear interpolated into $1 \mathrm{~km}$ grid cell.

\subsection{Site-condition Estimation}

The framework of site-condition determination is based on the method which was introduced in USGS 2007-1357 report. The method is based on the theory that more competent materials, showing high-velocity, are more likely to maintain a steep slope, whereas deep basin sediments are deposited primarily in environments with low gradients. A correlation of topography and site-condition is derived based on the data from California, Japan and Taiwan and applied on several other countries and regions, without mainland China.

In this study, as introduced in USGS 2007-1357 report, shuttle Radar Topography Mission (SMRT) data is applied to obtain maximum slope of a specific site in 30" grid(approximately $1 \mathrm{~km}$ grid). $\mathrm{Vs}^{30}$, the average shear-velocity down to $30 \mathrm{~m}$, can be acquired by correlations between $\mathrm{Vs}^{30}$ and slopes.

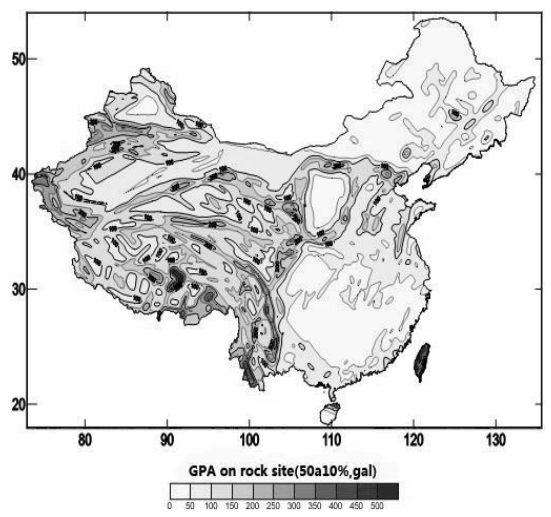

Figure 1. Rock-site GPA map for China(50a10\%)
Table 1. Summary of slope ranges for subdivided NEHRP Vs ${ }^{30}$ categories

\begin{tabular}{|c|c|c|c|}
\hline Class & $\begin{array}{c}\mathrm{V}_{\mathrm{s}}^{30} \\
\text { range(m } \\
/ \mathrm{s})\end{array}$ & $\begin{array}{c}\text { Slope } \\
\text { range(m/m)- } \\
\text { Active } \\
\text { Tectonic }\end{array}$ & $\begin{array}{c}\text { Slope } \\
\text { range }(\mathrm{m} / \mathrm{m})- \\
\text { Stable } \\
\text { Tectonic }\end{array}$ \\
\hline $\mathrm{E}$ & $<180$ & $<1.0 \mathrm{E}-4$ & $<2.0 \mathrm{E}-5$ \\
\hline \multirow{3}{*}{$\mathrm{D}$} & $180-240$ & $\begin{array}{c}1.0 \mathrm{E}-4-2.2 \mathrm{E}- \\
3\end{array}$ & $2.0 \mathrm{E}-5-2.0 \mathrm{E}-3$ \\
\cline { 2 - 4 } & $240-300$ & $\begin{array}{c}2.2 \mathrm{E}-3-6.3 \mathrm{E}- \\
3\end{array}$ & $2.0 \mathrm{E}-3-4.0 \mathrm{E}-3$ \\
\cline { 2 - 4 } & $300-360$ & $6.3 \mathrm{E}-3-0.018$ & $4.0 \mathrm{E}-3-7.2 \mathrm{E}-3$ \\
\hline \multirow{3}{*}{$\mathrm{C}$} & $360-490$ & $0.018-0.050$ & $7.2 \mathrm{E}-3-0.013$ \\
\cline { 2 - 4 } & $490-620$ & $0.050-0.10$ & $0.013-0.018$ \\
\cline { 2 - 4 } & $620-760$ & $0.10-0.138$ & $0.018-0.025$ \\
\hline \multirow{2}{*}{$\mathrm{B}$} & $>760$ & $>0.138$ & $>0.025$ \\
\hline
\end{tabular}

Active tectonic and stable tectonic in China were distinguished and mapped based on topography, plate movement, seismic activity(Shi Zhenliang, 1973 , 1995 ; Ma Xinghuan, 1989), which is showed in figure2.

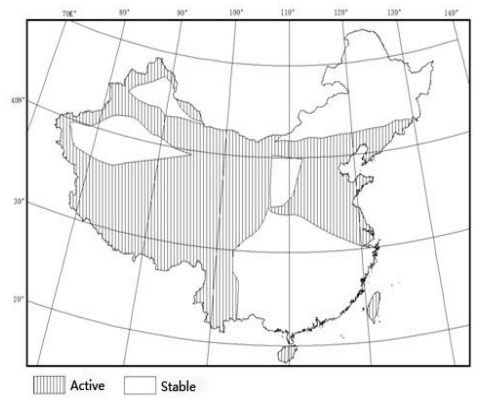

Figure 2. Active and Stable Tectonic Map for China

The $\mathrm{Vs}^{30}$ map for China, showed in figure 3 , was generated through applying the 2 correlations on SMRT data. The Vs ${ }^{30}$ map for China indicates that regions with low-velocity surficial materials are located at alluvial plain of Yellow river and Huai river in east China, North-east China, and Xinjiang region, while high-velocity regions which indicated mountains and hills are located at Southern and south-west China. 


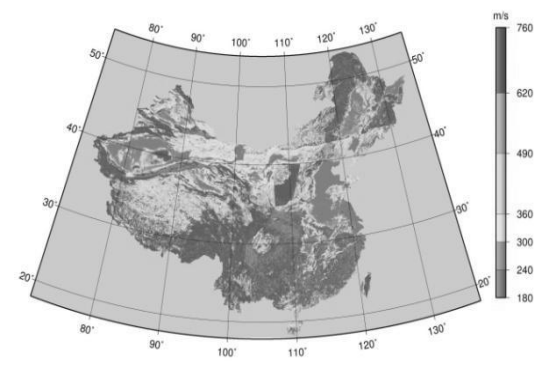

Figure 3. Vs30 map of China derived from topographic slope

\subsection{Amplification Factors}

The target for deriving the $\mathrm{Vs}^{30}$ distribution comes from the need to acquire the site amplification in every grid cell, which can be applied with GPA map on rock site to generate hazard map. The Short-period site amplification factors were assigned to each grid by applying the amplification factors of Borcherdt(1994), which showed in table 2.

Table 2. Short-period (0.1-0.5s) and midperiod (0.4-2.0s) site amplification factors

\begin{tabular}{|c|c|c|c|c|c|}
\hline Class & $V_{s}$ & \multicolumn{4}{|c|}{ Short-period $(P G A)$} \\
\hline$\underset{*}{P G A}$ & & & 150 & 250 & 350 \\
\hline B & 686 & 1.00 & 1.00 & $\begin{array}{c}1.0 \\
0\end{array}$ & 1.00 \\
\hline $\mathrm{C}$ & 464 & 1.15 & 1.10 & $\begin{array}{c}1.0 \\
4\end{array}$ & 0.98 \\
\hline $\mathrm{D}$ & 301 & 1.33 & 1.23 & $\begin{array}{c}1.0 \\
9\end{array}$ & 0.96 \\
\hline E & 163 & 1.65 & 1.43 & $\begin{array}{c}1.1 \\
5\end{array}$ & 0.93 \\
\hline
\end{tabular}

\subsection{Site GPA Map for China}

Based on rock-site ground motion information and site-condition and amplification in each $1 \mathrm{~km}$ grid cell in whole China, site GPA map for China, which uses $50 \mathrm{a} 10 \%$ and $100 \mathrm{a} 1 \%$ ground peaking acceleration(GPA) as parameter, is generated.

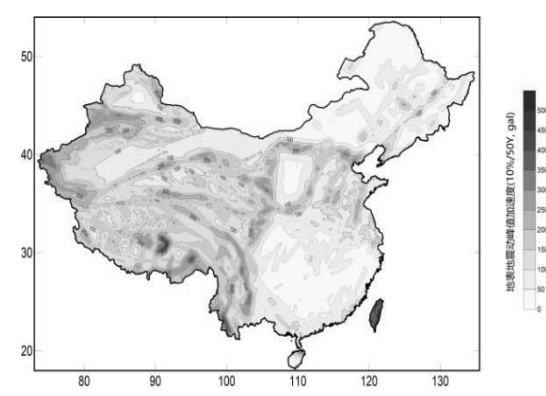

Figure4. Site GPA Map for

China(50a10\%,gal)

\subsection{Generating Building Earthquake Risk Map for China}

The motivation for creating the site GPA map for China comes from a practical need to produce the Building Earthquake Risk Map for Mainland China, which combines the earthquake hazard with building vulnerability and exposure, indicates predicted earthquakelosses in mainland China, and is useful for informed decision-making on mitigation policies, priorities, strategies for authorizes and publics.

The building information of mainland China, including structure type, story number, floor area, and construction time, is generated from $5^{\text {th }}$ national population census and $6^{\text {th }}$ national population census database. Data is also linear interpolated into $1 \mathrm{~km}$ grid cells.

A series of vulnerability matrixes based on structure type, intensity and location are also introduced in this study to estimate the vulnerability of buildings. Land use, population, and gross domestic product are taken into account in creating these matrixes.

Applying the vulnerability matrixes and database of buildings into the Site GPA Map for China, Building Earthquake Risk Map for Mainland China is generated. Building Earthquake Risk Map for Mainland China has 2 indexes to indicate the risk level: estimated economic losses and earthquake casualties, both derived from the losses to the general building stock. Red grid cells in the maps 
mean under the specialized probability level(50a10\%\&100a1\%) of earthquake ground motion effect, the economic losses\& earthquake casualties in these cells is high, while green grid cells mean low and white grid cells mean zero.

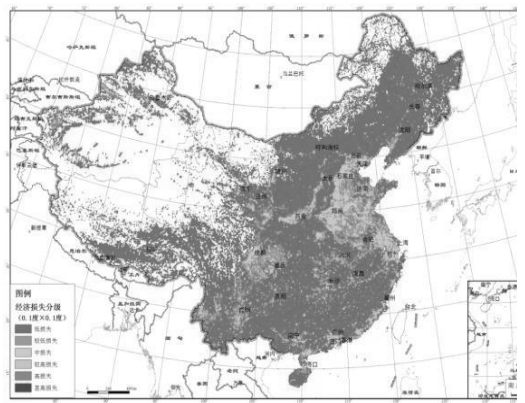

Figure 5. Building Earthquake Risk Map for Mainland China(economic losses at $50 \mathrm{a} 10 \%)$

\section{Application in Regional Scale}

In this study, a case study of Songming, Yunnan Province in south-west China, is performed to demonstrate the implementation and advantage using proposed USGS 2007 1357 report method for regional site-condition estimationand regional earthquake risk assessment.

\subsection{Information of Ground Motion on}

\section{Rock Site}

Like application in national scale, information of ground motion on rock site is derived from the result of Seismic Ground Motion Parameter Zonation Map of China (GB18306-2015). While in this case, for corresponding with Code for Seismic Design of Buildings.(GB50011-2010) only the possibility level of $50 \mathrm{a} 10 \%$ is chosen to represent the earthquake hazard in study region.

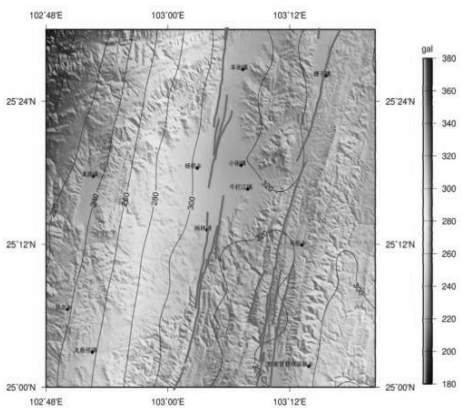

Figure 6. Peak ground motion on rock site in study area(50a10\%,gal)

\subsection{Site-condition in Regional Scale}

Like site-condition estimation in national scale, SMRT data is applied to obtain maximum slope of a site with 30" grid (approximately $1 \mathrm{~km}$ grid) cell in study region.

In regional scale, 92 drilling on 24 sites, in or around study region, offer direct shearwave observations in this study. 14 shear-wave observations in these 92 observations are $\mathrm{Vs}^{20}$ results. The method of estimating $\mathrm{Vs}^{30}$ from $\mathrm{Vs}^{20}$, introduced in Hangchuanchuan (2015), is applied to transform these Vs20 data to Vs30values.

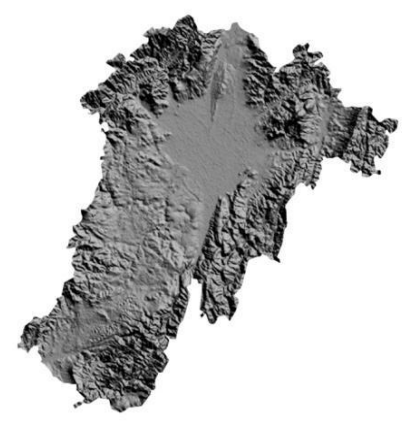

Figure 7. Digital Elevation Model derived from SMRT data

Then these measured $\mathrm{Vs}^{30}$ values are compared with values derived from topographic slope correlations to ensure the correlations is fit for study region. Referencing 
with local geologic map, in the area of Mesozoic group and earlier, the trend of measured $\mathrm{Vs}^{30}$ is relatively well-recovered using topographic slope, while in the area of Cenozoic, values derived from topographic slope correlations shows systematic high trend comparing with measured $\mathrm{Vs}^{30}$. For improving the result of estimation, the estimated values of $\mathrm{Vs}^{30}$ are adjusted by formula 1 .

$$
\mathrm{Y}=83+0.41 \mathrm{X}
$$

where $\mathrm{X}$ is the original estimated $\mathrm{Vs}^{30}$ value through topographic slope, $\mathrm{Y}$ is the adjusted value.

Adjusted topographic slope $\mathrm{Vs}^{30}$ map is showed in Figure 13. In the map, lower velocity region in the center indicated soft surficialmaterials where in field investigation is nearly-flat basin. High velocity region, around the low velocity region, indicated rock where in field investigation is mountains and hills.

\subsection{Site GPA Map in Study Region}

Short-period site amplification factors in regional scale is same as in national scale.

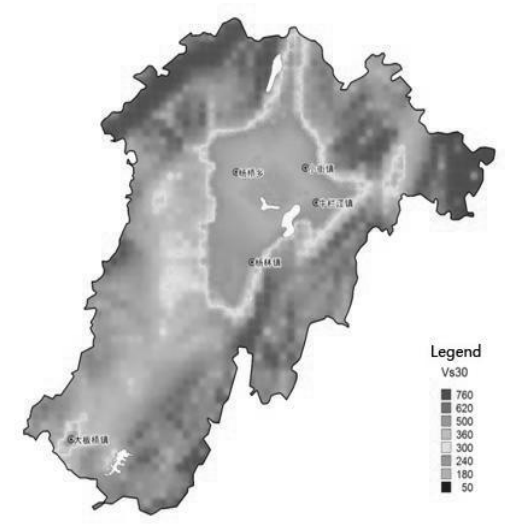

Figure 8. Adjusted topographic slope Vs30 map forSongming Yunnan Province

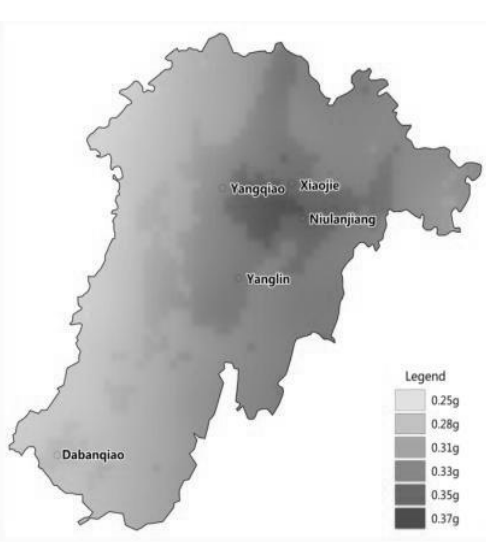

Figure 9.Hazard map forSongming, Yunnan Province

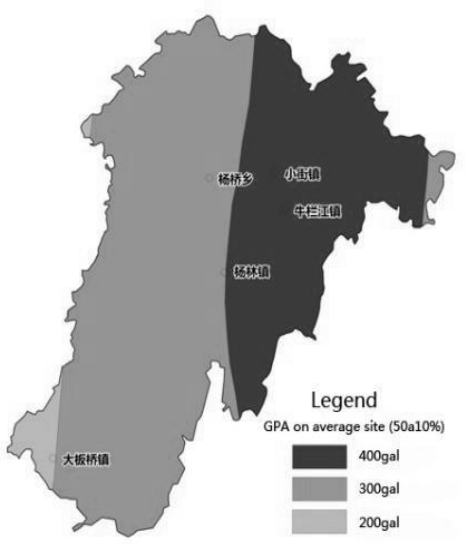

Figure 10.GPA map of Songming, YunnanProvince in Seismic Ground Motion Parameter Zonation Map of China (GB183062015)

Based on rock-site ground motion information, site-condition and amplification factors in each $1 \mathrm{~km}$ grid cell in study region. The hazard map for Songming, Yunnan Provence, which uses 50a10\%ground peaking acceleration(GPA) as parameter, is generated.

It is important to note that, comparing with the GPA results in Seismic Ground Motion Parameter Zonation Map of China (GB18306-2015), which does not reflect the difference of site-condition, the hazard map in 
this study highlights the influence and amplification of ground motion on soft surficial materials region.

\section{Conclusions}

As mentioned in USGS 2007-1357 report, the method of using topographic slope as a proxy for seismic site-conditions and amplification has significant value in the application of earthquake risk assessment in China, in national scale and regional scale.

In regional scale, the ground motion distribution which considered the variety of regolith and its amplification shows more details of local earthquake hazard distribution comparing to the results of Seismic Ground Motion Parameter Zonation Map of China (GB18306-2015), which based on average site. This rapid method of estimating site-condition offers a feasible approach of gaining sitecondition information which can use in timelimited urban planning.

Local modification to the correlations is provided to improve the accuracy. Restricted by the data-base of measured $\mathrm{Vs}^{30}$ information, this modification is preliminary. More data of measured $\mathrm{Vs}^{30}$ information, including drilling information from more than 10 years of seismic safety evaluation projects, will be collected in the future research. Moreover, other methods to demonstrate and modify the correlations, like GIS and geologic method,will be developed and applied in the future.

\section{References}

[1] China Earthquake Administration, General Administration of Quality Supervision Inspection and Quarantine of the PRC. seismic ground motion parameters zonation map of China . GB18306-2015, 2015.

[2] Allen T.I. and Wald D.J. Topographic Slope as a Proxy for Seismic SiteCondition $\left(\mathrm{V}_{\mathrm{s}}{ }^{30}\right)$ and Amplification around the Globe. U.S. Geological
Survey Open-File Report 20071357,69*, 2007

[3] Farr T.G., and Kobrick M. Shuttle radar topography mission produces a wealth of data. EOS Trans. ,2000, 81:583-585

[4] Kang C C, Yu Y X, Ma C, Li J L, Huang C C. Estimation methods of vs30 for drilling with depth less than 30 meters in Sichuan area. Technology for Earthquake Disaster Prevention, 2015, 10(2): 316-323.

[5] Borcherdt, R.D. Estimates of sitedependent response spectra for design (methodology and justification): Earthquake Spectra, 1994, 10(4): 613653.

[6] Ma Xinghuan. Modern Movement of Inplate Block. Lithospheric Dynamics Atlas of China. Beijing: Sinomap Press, 1989.

[7] Shi Z L, Huan W L, Wu H R, Cao X L. On the intensive seismic activity in China and its relation to plate tectonics. Chinese Journal of Geology, 1973, 4: 281-293

[8] Guo J, Huang C F. Time limit of the probabilistic risk for natural disaster. Journal of Risk Analysis and Crisis Response, 2017, 7(3):137-145. 